\title{
Familiar songs reduce infant distress
}

\author{
Laura K. Cirelli, Sandra E. Trehub
}

\author{
Version Post-print/Accepted Manuscript \\ Citation Cirelli, L. K., \& Trehub, S. E. (2020). Familiar songs reduce infant \\ (published version) distress. Developmental Psychology. Advance online \\ publication. https://doi.org/10.1037/dev0000917 \\ Copyright / License (C) 2020, American Psychological Association \\ Publisher's Statement This paper is not the copy of record and may not exactly replicate the \\ final, authoritative version of the article. Please do not copy or cite \\ without authors' permission. The final article will be available, upon \\ publication, via its DOI: https://doi.org/10.1037/dev0000917.
}


Running title: Familiar songs reduce infant distress

\title{
Familiar songs reduce infant distress
}

\author{
Laura K. Cirelli ${ }^{1}$, Sandra E. Trehub ${ }^{2}$ \\ ${ }^{1}$ Department of Psychology, University of Toronto Scarborough, Toronto, Canada \\ ${ }^{2}$ Department of Psychology, University of Toronto Mississauga, Mississauga, Canada
}

Address correspondence to Laura K. Cirelli, Department of Psychology, University of Toronto

Scarborough, 1265 Military Trail, Toronto, ON, M1C 1A4, Canada. 1-416-208-4784 (phone);

laura.cirelli@utoronto.ca. Data are available from the corresponding author upon request.

Acknowledgements: This research was funded by a grant from the Natural Sciences and Engineering Research Council of Canada to S.T. and by a postdoctoral fellowship from the Social Sciences and Humanities Research Council of Canada to L.C. Thanks to Diya Ahmad, Vishnija Asokan, Shaima Behery, Samantha Cottrell, Nirma Jbara, Alexandra Kljuseva, Jovana Miladinovic, Emma Smith, Chella Velkannan and Idila Yogeswaran for assistance with data collection and/or data coding. 


\title{
Familiar songs reduce infant distress
}

\begin{abstract}
Parents commonly vocalize to infants to mitigate their distress, especially when holding them is not possible. Here we examined the relative efficacy of parents' speech and singing (familiar and unfamiliar songs) in alleviating the distress of 8- and 10-month-old infants ( $n=68$ per age group). Parent-infant dyads participated in three trials of the Still Face procedure, featuring a 2-min Play phase, a Still Face phase (parents immobile and unresponsive for 1 min or until infants became visibly distressed), and a 2-min Reunion phase in which caregivers attempted to reverse infant distress by 1) singing a highly familiar song, 2) singing an unfamiliar song, or 3) expressive talking (order counterbalanced across dyads). In the Reunion phase, talking led to increased negative affect in both age groups, in contrast to singing familiar or unfamiliar songs, which increased infant attention to parent and decreased negative affect. The favorable consequences were greatest for familiar songs, which also generated increased smiling. Skin conductance recorded from a subset of infants ( $n=36$ younger, 41 older infants) revealed that arousal levels were highest for the talking reunion, lowest for unfamiliar songs, and intermediate for familiar songs. The arousal effects, considered in conjunction with the behavioral effects, confirm that songs are more effective than speech at mitigating infant distress. We suggest, moreover, that familiar songs generate higher infant arousal than unfamiliar songs because they evoke excitement, reflected in modestly elevated arousal as well as pleasure, in contrast to more subdued responses to unfamiliar songs.
\end{abstract}

Keywords: infants, singing, affect regulation, still face procedure, skin conductance 
The use of music listening for emotional self-regulation-mood enhancement, distraction, and relaxation - is widespread from adolescence through old age (Cohrdes, Wrzus, \& Riediger, 2017; Lonsdale \& North, 2011; Saarikallio \& Erkkilä, 2007). Toddlers and preschoolers use music for emotional self-regulation, whether singing spontaneously during solitary play (Dean, 2019) or in the crib after separation from family members (Sole, 2017). Because infants' self-regulation abilities are relatively limited, parents' role is critical in regulating infant moods or emotions.

In fact, parents' role in infant emotion regulation has implications beyond infancy. For example, their responsiveness to infant distress is thought to influence dyadic bonding and the development of self-regulation skills (Bell \& Ainsworth, 1972; Eisenberg, Cumberland, \& Spinrad, 1998; Jahromi \& Stifter, 2007; Zeifman, 2015). In human and nonhuman species, infant crying prompts maternal attention, proximity, and vocalization (Bornstein et al., 2017; Jovanovic, Megna, \& Maestripieri, 2000; Lingle \& Riede, 2014). Although holding or carrying is the most effective strategy for reducing distress in human infants, vocalization is another common intervention (Bornstein et al., 2017; Esposito et al., 2013; Jahromi \& Stifter, 2007), either in conjunction with holding or where holding is precluded (Falk, 2004). The present study explored the efficacy of caregivers' speech and familiar and unfamiliar songs for ameliorating infant distress and regulating arousal.

Non-distressed infants exhibit greater attention to infant-directed (ID) vocalizationssong as well as speech — than to self-directed (SD) or adult-directed (AD) vocalizations (Cooper \& Aslin, 1990; Fernald, 1985; Trainor, 1996). ID vocalizations typically have higher fundamental frequency, slower tempo, and greater emotional expressiveness than SD or AD vocalizations (Fernald \& Simon, 1984; Nakata \& Trehub, 2011; Trainor, 1996). Because 
distraction effectively reduces infant distress (Cohen, 2002), the attention-eliciting properties of ID vocalizations may be suitable for ameliorating distress. Live ID song may be especially effective because audiovisual ID song captures infant attention more effectively than audiovisual ID speech (Costa-Giomi, 2014; Nakata \& Trehub, 2004).

Caregivers talk to infants considerably more than they sing to them, but such singing is widespread, probably universal (Mehr et al., 2019). Caregivers' songs are highly stable in pitch level and tempo across occasions, unlike speech to infants, which exhibits considerable variability in form and content (Bergeson \& Trehub, 2002). Nevertheless, caregivers' speech exhibits some distinctive melodic signatures that are repeated at different times with different verbal content (Bergeson \& Trehub, 2007). Perhaps the most prominent difference between the two modes of vocalization is the absence of beat-based regularity in speech and its dominance in ID singing (Longhi, 2009; Nakata \& Trehub, 2011) and music in general (Savage, Brown, Sakai, \& Currie, 2015). Although ID speech incorporates more repetition than adult-directed speech, it lacks the extensive repetition that characterizes music, a feature that adds to its appeal and memorability (Johnston, 2016; Margulis, 2013, 2014). Stereotypy and repetition in ID singing may contribute to its efficacy in regulating infant arousal (Cirelli, Jurewicz, \& Trehub, 2019; Shenfield, Trehub, \& Nakata, 2003) and its greater efficacy than ID speech in delaying the onset of infant distress (Corbeil, Trehub, \& Peretz, 2016). Specifically, listening to an unfamiliar ID song rather than an ID recitation of the lyrics substantially increases infants' latency to cry (Corbeil et al., 2016).

There is suggestive evidence that caregivers' singing is more effective than their speech for regulating the affect and arousal of distressed infants. In a doctoral dissertation that explored this question (Ghazban, 2013), mothers and their 10-month-olds participated in a modified still 
face procedure (Adamson \& Frick, 2003; Mesman, van Ijzendoorn, \& Bakermans-Kranenburg, 2009; Tronick, Als, Adamson, Wise, \& Brazelton, 1978) featuring mother-infant interaction, maternal unresponsiveness, and the resumption of interaction dominated by ID speech or singing. ID song was more effective than ID speech at reducing overt negative affect and physiological arousal.

Caregivers' singing may be more effective than speech at ameliorating infant distress because of its stereotypy, repetition, and consequent memorability. Indeed, memory for music is surprisingly robust in infancy. Newborns recognize melodies after systematic prenatal exposure (Partanen, Kujala, Tervaniemi, \& Huotilainen, 2013). At 2 months, they recognize familiar instrumental melodies after minimal exposure (Plantinga \& Trainor, 2009), and at 6 months, they recognize previously familiarized instrumental melodies when presented at a novel pitch level (Plantinga \& Trainor, 2005). After one or two exposures, adults and children remember vocal renditions of melodies (sung to la la) better than instrumental renditions (Weiss, Trehub, \& Schellenberg, 2012; Weiss, Trehub, Schellenberg, \& Dawber, 2015). Moreover, after 5-montholds hear songs intermittently during a 1- or 2-week period, they recognize them several months later, distinguishing them from other songs with the same rhythm and lyrics but different tune (Mehr, Song, \& Spelke, 2016).

Familiar songs have social significance for infants (Cirelli \& Trehub, 2018; Mehr et al., 2016; Mehr \& Spelke, 2017). For example, 5-month-olds look longer at a woman after she sings a familiar song rather than an unfamiliar song, but only if their parent was the source of familiarization; no such effect is evident when familiarization is achieved by means of a recording emanating from a toy (Mehr et al., 2016). Moreover, 14-month-olds provide more help to unfamiliar singers who sing a familiar song from their parent's repertoire than when they sing 
an unfamiliar song (Cirelli \& Trehub, 2018). The impact of song familiarity on early social behavior may underlie its life-long effects on emotion regulation and extramusical memories (Pereira et al., 2011; van den Bosch, Salimpoor, \& Zatorre, 2013).

In the present study, we examined the impact of caregivers' songs, familiar and unfamiliar, and speech on attention, affect, and arousal in distressed 8- and 10-month-olds. Caregivers engaged in 2 min of Play with infants followed by a stress-inducing Still Face manipulation ( 1 min or less) and a 2-min Reunion episode in which caregivers 1 ) sang a highly familiar song, 2) sang a song familiar to them but unfamiliar to infants, or 3) spoke expressively while attempting to alleviate infants' distress. Infant behavior and arousal (skin conductivity) were recorded continuously. Because skin conductance reflects sympathetic nervous system arousal without regard to valence (positive or negative), it must be evaluated in conjunction with behavioral responses. Based on previous research with infants (Corbeil et al., 2016; CostaGiomi, 2014; Ghazhan, 2013; Nakata \& Trehub, 2004; Trehub, Plantinga, \& Russo, 2016) and on the greater temporal regularity, repetitiveness, and memorability of music relative to speech (Margulis, 2014), we expected multimodal sung performances, familiar and unfamiliar, to be more effective at capturing and maintaining infant attention and more effective at reducing infant distress and arousal than multimodal speech. Because of the social and emotional significance of familiar songs for infants (Cirelli \& Trehub, 2018; Mehr et al., 2016, 2017), the stereotypy of caregivers' repeated performances (Bergeson \& Trehub, 2002), and infants' enduring memory for songs (Mehr et al., 2016), we expected familiar songs to regulate infant attention, affect, and arousal more effectively than unfamiliar songs. 


\section{Method}

\section{Participants}

Participants were caregiver-infant dyads from middle-class families in a Canadian suburb, specifically 8-month-olds $(N=70, M=7.88$ months, $S D=0.39$, 32 girls $), 10$-month-olds $(N=70, M=9.87$ months, $S D=0.30,35$ girls $)$ and their primary caregivers $(136$ mothers, 4 fathers, $M$ age $=33.03$ years, $S D=3.83,4$ ages undisclosed $)$. All infants were born at term $(37+$ weeks gestation), and no parent reported infant hearing or vision problems. All parents reported singing regularly to their infants $(M=315 \mathrm{~min}$ per week, range $=15-1750 \mathrm{~min})$. Data from 28 additional infants were excluded because of fussiness and consequent failure to complete the task $(N=20)$ or parents' failure to follow instructions $(N=8)$. Data collection continued until clean skin conductance (SC) samples were obtained from at least 36 infants in each age group, balanced across the 6 order conditions (described below). This a priori stopping rule ensured that at least 6 infants received each order in each age group. With power $=0.8$, this allowed us to detect an effect size f as small as 0.15 (G*Power, Faul, Erdfelder, Lang, \& Buchner, 2007). The University of Toronto Research Ethics Board approved all data collection procedures (protocol \# 00033547, “Infant-directed singing: Emotional and social benefits"), and informed consent was obtained from all caregivers.

\section{Apparatus}

Testing took place in a double-walled sound-attenuating booth (Industrial Acoustics) with parent and infant seated facing each other. Caregivers wore a Sony lapel microphone (ECM55B) and Sony in-ear headphones (MDREX15LP) with disposable tips connected to an audio interface (Edirol UA-4FX ). The experimenter (E) outside the booth monitored input from the caregiver's lapel mic via Sony headphones (Sony MDR-7506) and communicated to the 
caregiver via Audio Interface running on a Mac OSX computer and its internal microphone. A smartphone application (Multitimer) timed each section of the experiment. E communicated with the caregiver when each phase ended, providing instructions for the next phase (e.g., "Now start singing the baby's favorite song").

BIOPAC MP160 in conjunction with AcqKnowledge 5.0 software running on a Windows 10 computer recorded infant SC at a sampling rate of $100 \mathrm{~Hz}$. Video and audio from infant and caregiver were recorded simultaneously through AcqKnowledge with two Sony Exmor R camcorders. Electrodes were placed on the plantar surface of the infant's right foot, and the amplifiers were worn around the right calf. The amplifier was held in place by a folded cuff on customized infant pants. Electrodes were secured with paper medical tape, and a sock was placed on the infant's foot and over the amplifier to cover the wires.

\section{Procedure}

Before visiting the lab, parents were informed that they would be singing their infant's favorite song as well as another song well-known to them but unknown to the infant. A list of 38 common children's songs was provided to facilitate parents' song selection, but parents were free to select other songs. The laboratory visit began with E obtaining consent and explaining the caregiver's role in each phase (Play, Still Face, Reunion) of the study. Caregivers were informed that there would be three back-to-back trials, and that during the reunion phase they would speak to the infant, sing them their favorite song, or sing the unfamiliar song in a specific order, as prompted. The infant was then placed in a highchair in the sound-attenuating room and the caregiver sat 1-m away, facing the infant. E applied electrodes to the infant's foot while an assistant (A) fitted the caregiver with the audio equipment. E and A left the test suite, and testing began. 
The test session ( $20 \mathrm{~min})$ consisted of three trials, each with three phases: (1) Play Phase (minimum $2 \mathrm{~min}$ ): caregivers used simple toys to engage infants. Infants had to display neutral or positive mood for at least $30 \mathrm{~s}$ before the next phase began. The play phase was extended beyond $2 \mathrm{~min}$ if necessary ( $6 \%$ of trials). If infants did not meet the mood criterion within a few minutes, testing was terminated. (2) Still Face Phase (maximum $1 \mathrm{~min}$ ): caregivers removed the toys, turned their head leftward, adopted a neutral expression, and turned back to face the infant after $5 \mathrm{~s}$ while maintaining a neutral expression without moving, vocalizing, or touching the infant. This phase continued until 1 min elapsed unless the infant reached the distress criterion (sustained fussing or crying for $10 \mathrm{~s} ; 50 \%$ of trials) earlier, in which case the next phase began immediately. (3) Reunion Phase (2 min): caregivers tried to console infants by sustained expressive speech (talking condition) but no singing, repeatedly singing the infant's favorite song (familiar song condition), or repeatedly singing the unfamiliar song (unfamiliar song condition). In all conditions, parents were free to use nonverbal gestures and touching, but they could not remove the infant from the highchair. The order of the three within-subjects conditions was counterbalanced across infants. When the Reunion ended, the caregiver retrieved the toys to start the next Play Phase.

\section{Data Processing}

Behavior. Videos were unavailable for 2 of the 70 8-month-olds and 2 of the 7010 month-olds because of equipment failure. Video clips from the infant-facing camera were trimmed to show the last 30 s of Play, last 10 s of Still Face, and four 30-s segments of Reunion (R1, R2, R3, R4). Clips were loaded into ELAN 5.1 (Lausberg \& Sloetjes, 2009; https://tla.mpi.nl/tools/tla-tools/elan/), where they were epoched into 5-s clips. Raters blind to the hypotheses and conditions coded these clips for infant attention to parent, smiling, and negative 
affect. Means for each measure were calculated for each infant in each condition (talking, familiar song, unfamiliar song) for Play, Still Face, and each 30-s segment of Reunion. Video clips from the parent-facing camera were also coded. Details of parent behavior coding are available in Supporting Information.

Attention to parent. Raters watched each 5-s clip without audio and assigned a score of 1 to clips in which infants looked directly at parents and 0 to clips with no such looking. A second coder, blind to condition, rated $20 \%$ of clips (92\% agreement).

Smiling. Raters watched each 5-s clip without audio, assigning a score of 1 to clips with infant smiling and 0 to clips with no smiling. A second coder, blind to condition, rated $20 \%$ of clips (93\% agreement).

Negative affect. Infant negative affect included crying, frowning, whining, anger, and apparent frustration. A rater watched each 5-s clip (with audio) and rated, on 0-4 Likert scales, duration of negative affect $(0$ - no negative affect; 4 - negative affect for the entire $5 \mathrm{~s})$ and its intensity ( 0 - no negative affect; 1 - mild intensity; 4 - high intensity). These two scores were multiplied to generate a composite score of duration and intensity of negative affect. A second coder, blind to condition, rated $20 \%$ of the clips without audio and achieved high interrater reliability, $r=.895, p<.001$.

Skin conductance. SC data were downsampled to $10 \mathrm{~Hz}$ in the Ledalab (V3) toolbox running in Matlab 2016a. Trials with extreme artifacts were visually identified and removed from further SC analyses, and minor artifacts were corrected. Clean SC recordings were retained for 36 8-month-olds and 41 10-month-olds. Tonic SC was extracted using Continuous Decomposition Analysis (Benedek \& Kaernbach, 2010) and processed further in the Matlab 
workspace. For each infant, tonic SC was normalized to standard $z$-scores, and mean $z$-scores calculated for the last 30-s of Play, last 10-s of Still Face, and the four segments of Reunion.

\section{Results}

Greenhouse-Geisser corrections are reported when sphericity was violated in mixeddesign ANOVAs.

\section{Song selections}

Parents largely sang playsongs, with considerable song overlap across parents and conditions. The most popular favorite songs were Itsy Bity Spider, sung by 18 parents, Baby Shark (12) and If You're Happy and You Know It (12), and the most common unfamiliar song was Row, Row, Row Your Boat (12). Further information about parents' songs is provided in Supporting Information.

\section{Still Face Intervention}

For the 140 infants who completed the procedure, the number of infants reaching the distress criterion (sustained fussing or crying for $10 \mathrm{~s}$ ) before $60 \mathrm{~s}$ increased progressively over trials (27, 81, and 100 for trials 1, 2, and 3, respectively), resulting in a mean Still Face duration of 54,41 , and $34 \mathrm{~s}$ for trials 1,2 , and 3 , respectively, $p<.001$.

To assess the efficacy of the stress-inducing manipulation, $\mathrm{SC}$ and behavior were compared across the within-subjects factors of time (from Play to the last $10 \mathrm{~s}$ of Still Face) and vocal style (talking, familiar song, unfamiliar song) as well as the between-subjects factor of age group (younger, older) with mixed-design ANOVAs. For attention to parent, smiling, and SC, there were no main effects or interactions with vocal style or age $(p s>.065)$, but there were significant main effects of time. From Play to Still Face, attention to parent increased, $F(1,134)$ $=17.69, p<.001, n_{\mathrm{p}}^{2}=.12 ;$ smiling decreased, $F(1,134)=47.66, p<.011, n_{\mathrm{p}}{ }^{2}=.26 ;$ and 
arousal level (SC) increased, $F(1,75)=44.95, p<.001, n_{\mathrm{p}}^{2}=.38$. For negative affect, there was a three-way interaction among vocal style, age, and time, $F(2,268)=4.07, p=.018, n_{\mathrm{p}}{ }^{2}=.03$. In all conditions and age groups, infants displayed more negative affect in Still Face than in Play (all $p \mathrm{~s}<.001)$. In the talking condition, however, older infants showed more negative affect during Still Face than younger infants, uncorrected $p=.007$. Overall, the Still Face effectively elicited infant distress.

\section{Behavior During Reunion}

Attention to parent. Attention to parent during Play, Still Face, and each 30-s segment of Reunion is shown in Figure 1. Attention to parent during Reunion was analyzed with a mixeddesign ANOVA with time (R1, R2, R3, R4) and vocal style (talking, familiar song, unfamiliar song) as within-subjects factors and age (younger, older) as a between-subjects factor. There was a main effect of age, $F(1,134)=13.46, p<.001, n_{\mathrm{p}}{ }^{2}=0.09$, with older infants exhibiting more attention to parent $(M=0.60, S D=0.16)$ than younger infants $(M=0.48, S D=0.21)$. There were no significant interactions between age and time or vocal style, $p \mathrm{~s}>.27$.

There were significant effects of vocal style, $F(2,268)=21.05, p<.001, n_{\mathrm{p}}{ }^{2}=0.14$, and time, $F(2.80,374.36)=23.49, p<.001, n_{\mathrm{p}}{ }^{2}=0.15$, qualified by an interaction between vocal style and time, $F(6,804)=2.60, p<.017, n_{\mathrm{p}}{ }^{2}=0.02$. Simple main effects of vocal style at each timepoint explored this interaction, with Bonferroni-adjusted alpha levels of 0.017 per test $(0.5 / 3)$ for post-hoc contrasts. In the first $30 \mathrm{~s}$ of Reunion $(\mathrm{R} 1)$, infant attention differed significantly across vocal styles. The familiar song was most effective in capturing infant attention and talking least effective, with the unfamiliar song intermediate (all $p \mathrm{~s}<.003$ ). In R2, the familiar song captured infant attention more effectively than talking, $p<.001$, or the unfamiliar song, $p=.006$, but the unfamiliar song did not differ from talking. This pattern 
persisted in R3, but by R4, the only significant difference was between the familiar song and talking, $p=.002$.

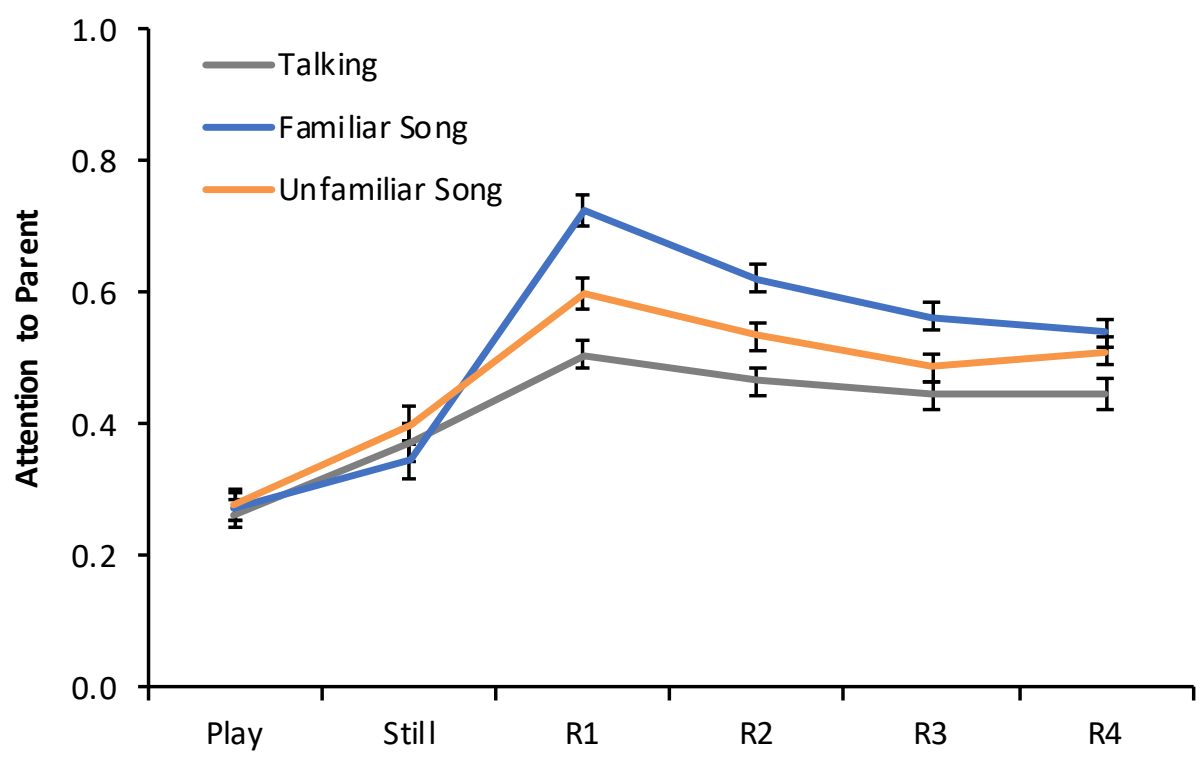

Figure 1: Mean attention to parent across the last 30-s of Play, last 10-s of Still Face, and successive 30-s intervals of Reunion. Reunion analyses revealed highest attention for the familiar song, intermediate for the unfamiliar song, and least for talking. Error bars represent withinsubjects standard error of the mean.

Smiling. Smiling during Play, Still Face, and each 30-s segment of Reunion is shown in Figure 2. Infant smiling during Reunion was analyzed using a mixed-design ANOVA with time (R1, R2, R3, R4) and vocal style (talking, familiar song, unfamiliar song) as within-subjects factors and age (younger, older) as a between-subjects factor. There was no main effect of age or interaction between age and vocal style or age, vocal style, and time ( $p$ s $>.136)$, but there was a significant interaction between age and time, $F(2.47,331.34)=7.80, p<.001, n_{\mathrm{p}}{ }^{2}=0.06$, driven 
by greater smiling in younger $(M=0.15, S D=0.15)$ than in older $(M=0.09, S D=0.13)$ infants at $\mathrm{R} 1, p=.017$, but at no other timepoints, $p \mathrm{~s}>.233$.

There were main effects of vocal style, $F(1.68,224.78)=24.64, p<.001, n_{\mathrm{p}}{ }^{2}=0.16$, and time, $F(2.47,331.34)=8.60, p<.001, n_{\mathrm{p}}{ }^{2}=0.06$, qualified by an interaction between vocal style and time, $F(4.37,585.34)=6.95, p<.001, n_{\mathrm{p}}{ }^{2}=0.05$. This interaction was explored further by examining simple main effects of vocal style at each timepoint, using post-hoc contrasts with Bonferroni-adjusted alpha levels of 0.017 per test (0.5/3). In R1, R2, and R3, infants smiled more during familiar songs than during unfamiliar songs or talking, $p \mathrm{~s}<.001$, which did not differ, $p \mathrm{~s}$ $>$.399. By R4, however, smiling to familiar songs had decreased, differing significantly only from unfamiliar songs, $p=.001$.

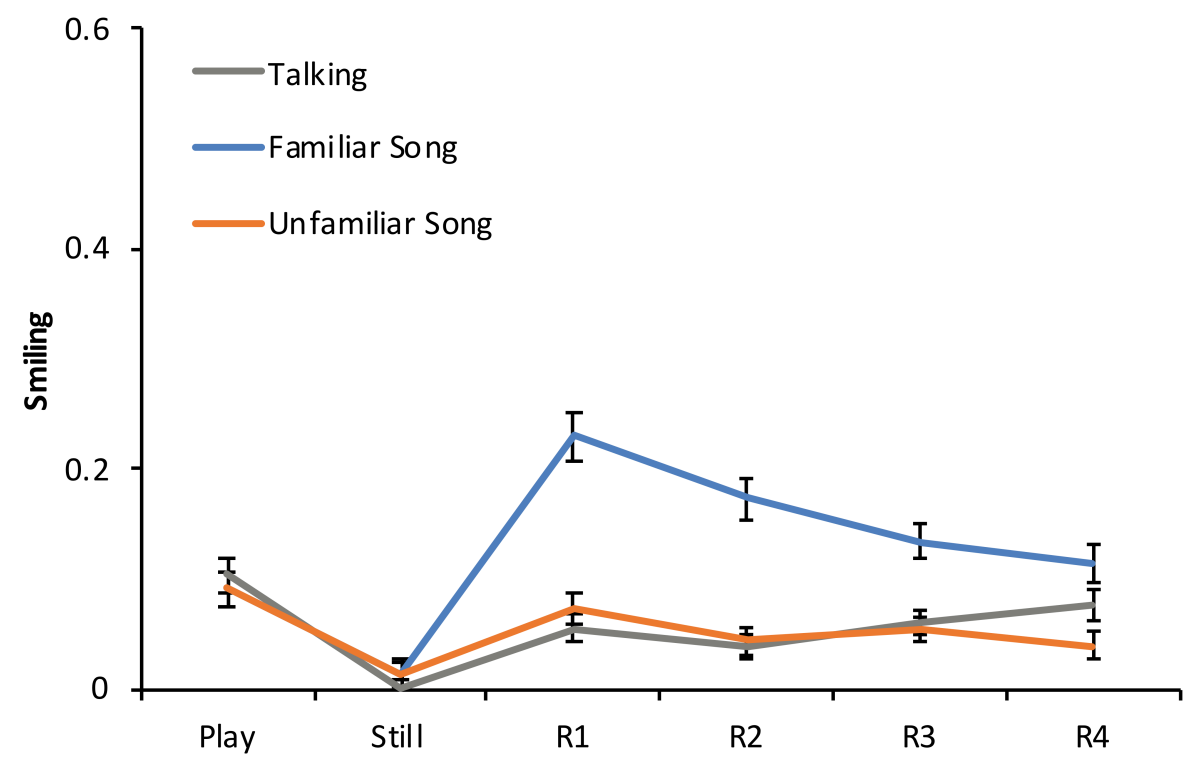

Figure 2: Mean smiling across the last 30-s of Play, last 10-s of Still Face, and 30-s intervals of Reunion. Analyses confirmed most smiling for the familiar song during Reunion. Error bars represent within-subjects standard error of the mean. 
Negative affect. Negative affect during Play, Still Face, and each 30-s segment of Reunion is shown in Figure 3. Negative affect during Reunion was analyzed using a mixeddesign ANOVA with time (R1, R2, R3, R4) and vocal style (talking, familiar song, unfamiliar song) as within-subjects factors and age (younger, older) as a between-subjects factor. There were significant effects of vocal style, $F(2,268)=17.61, p<.001, n_{\mathrm{p}}^{2}=0.12$, and time, $F(2.06$, $275.59)=12.57, p<.001, n_{\mathrm{p}}^{2}=0.09$, but no effect of age and no interactions, $p \mathrm{~s}>.191$. Although negative affect increased across Reunion, ratings were lowest for familiar songs, moderate for unfamiliar songs, and highest for talking. Negative affect ratings during Still Face were compared with ratings during R1 by means of paired-samples $t$-tests. Negative affect decreased significantly for familiar and unfamiliar songs $(p s<.001)$ but not for talking, $p=.256$.

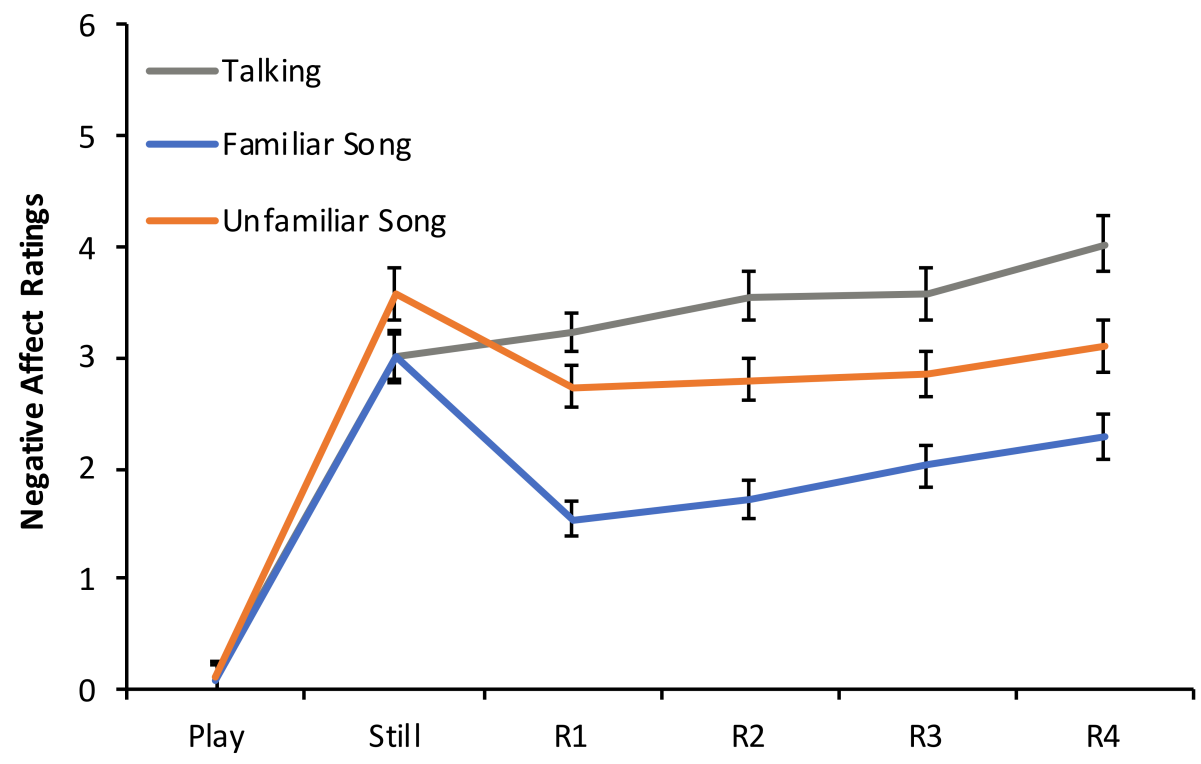

Figure 3: Mean negative affect rating across the last 30-s of Play, last 10-s of Still Face, and the 30-s intervals of Reunion. The familiar song mitigated distress most successfully followed by the unfamiliar song. Error bars represent within-subjects standard error of the mean. 
Parent behavior. Parent touch, rhythmic movement, smiling, and gesture use were coded (see Supporting Information for further details). Notably, parents touched infants more during talking than during familiar or unfamiliar songs. Rhythmic movement and smiling were less frequent during talking than in either song condition, and more frequent during familiar than unfamiliar song. Parents smiled less and touched infants more during the talking reunion relative to the play phase, most likely prompted by differences in infant affect (positive during play, negative during reunion).

\section{Skin Conductance}

To analyze SC during Reunion, mean SC during the last 10 s of Still Face was subtracted from Reunion values to reveal SC changes from final Still Face levels (see Figure 4). Positive values indicate continued arousal increases, and negative values indicate arousal decreases relative to Still Face levels. Reunion SC responses were analyzed using a mixed-design ANOVA with time (R1, R2, R3, R4) and vocal style (talking, familiar song, unfamiliar song) as withinsubjects factors and infant age (younger, older) as a between-subjects factor. There were significant effects of vocal style, $F(2,150)=6.05, p=0.003, n_{\mathrm{p}}{ }^{2}=0.08$, and age, $F(1,75)=$ 4.97, $p=.029, n_{\mathrm{p}}{ }^{2}=0.06$. Older infants had higher SC $(M=28, S D=0.38)$ than younger infants $(M=0.07, S D=0.42)$ during Reunion. Talking resulted in significantly higher SC levels than unfamiliar song, $p=.001$, and familiar song resulted in moderate SC levels that did not differ from those for talking, $p=.131$, or unfamiliar song, $p=.052$. There were no effects of time, $p=$ .129 , and no interactions, $p \mathrm{~s}>.104$.

To capture changes in arousal from the end of Still Face to Reunion, one-sample tests compared mean SC to 0 (i.e., no change) across the four Reunion timepoints. For talking and 
familiar song, arousal was above Still Face levels $(p<.001$ and $p=.005$, respectively). For unfamiliar songs, arousal did not differ significantly from Still Face $(p>.800)$.

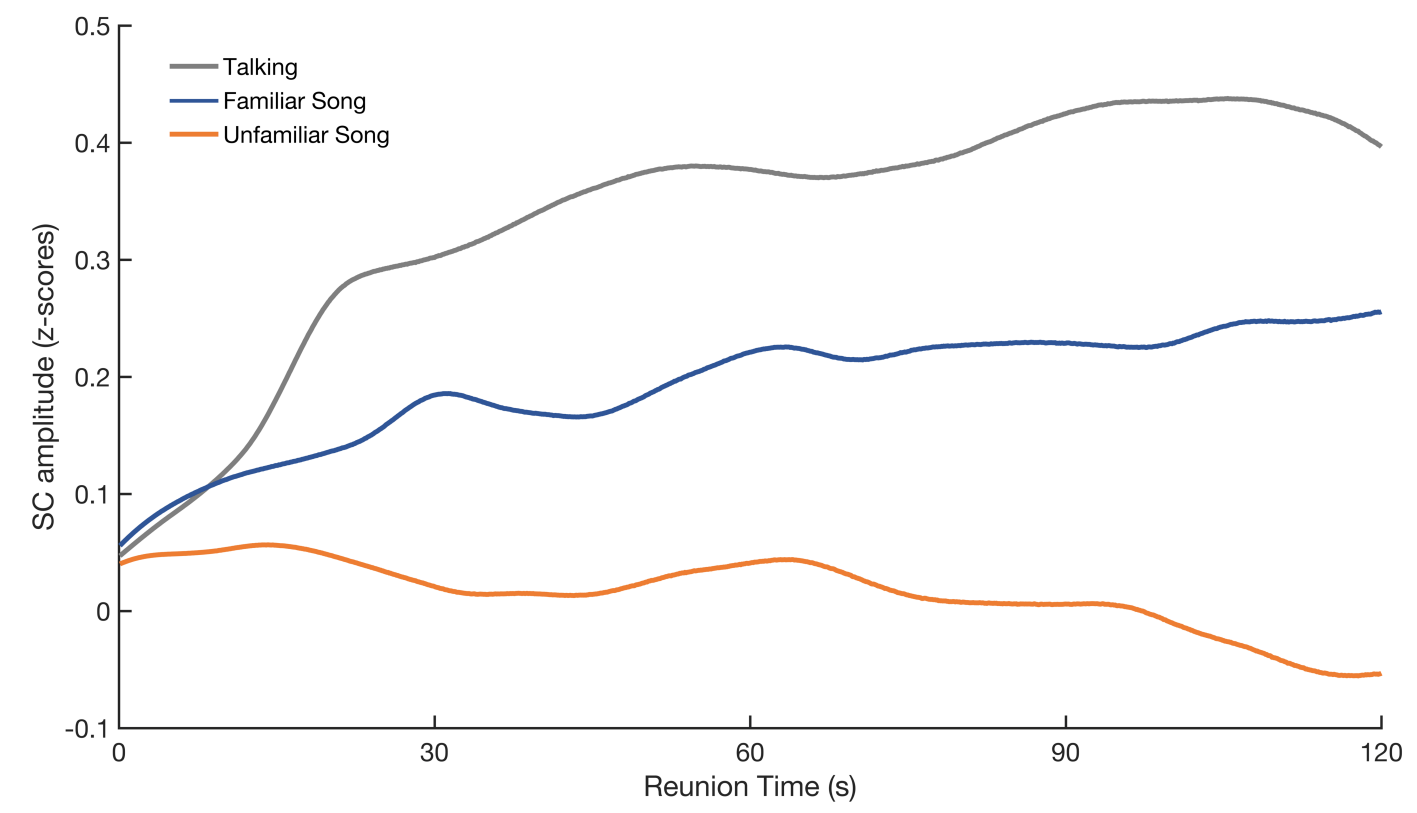

Figure 4: Difference SC scores for Reunion (Reunion values minus Still Face values).

\section{Discussion}

The goal of the present study was to examine the relative efficacy of parental songs, familiar and unfamiliar, and parental speech in reducing infant distress and arousal. Familiar songs were more successful at attenuating infant distress generated by the still-face procedure than were unfamiliar songs or speech. Specifically, familiar songs were best at capturing infants' attention, reducing overt distress, and promoting smiling, the effects being most pronounced during the first $30 \mathrm{~s}$ of the reunion, which typically featured one or two repetitions of a song.

Arousal levels increased from Play to Still Face, as expected, in line with the behavioral data. Nevertheless, arousal levels continued to increase during Reunion for the familiar song and talking conditions. Because arousal levels are uninformative about valence (positive, negative), 
behavioral data are necessary to contextualize these effects. For example, elevated arousal can result from high positive affect (e.g., engagement) or negative affect (i.e., distress), and low arousal can result from relaxation or disengagement. Accordingly, a plausible interpretation of the present findings is that infants' distress response to Still Face, reflected in high arousal and negative valence, was transformed into recognition and excitement when parents sang their favorite song, reflected in high arousal and positive valence. Regardless of their familiarity, songs were more effective in reducing distress than was speech, presumably because of the temporal regularity and repetitive nature of song — that is, highly predictable behavior following the highly unpredictable Still Face.

Spoken interactions were least effective in reducing infant distress. In fact, such interactions generated persistent distress and high arousal, in line with the reported carry-over effects of still-face interventions (Weinberg \& Tronick, 1996). Parental speech to distressed infants featured less smiling and more touch than speech to contented infants (last $30 \mathrm{~s}$ of the play phase), with parental touch presumably prompted by infant distress. Speech reunions were also least effective at capturing infant attention, as indexed by visual fixation of parent. In previous research, audio-only renditions of infant-directed speech captured the attention of nondistressed infants as effectively as infant-directed singing (Corbeil, Trehub, \& Peretz, 2013; Costa-Giomi \& Ilari, 2014), but audiovisual recordings favored singing over speech for nondistressed infants (Costa-Giomi, 2014; Nakata \& Trehub, 2004).

Singing an unfamiliar song was intermediate in its consequences for overt distress. Unfamiliar songs captured infant attention and reduced distress more effectively than talking but less effectively than familiar songs. Unfamiliar songs, unlike familiar songs, did not promote infant smiling. It may seem puzzling that arousal was lower for unfamiliar songs than for 
familiar songs. We suggest that familiar songs elicited greater excitement (higher arousal) and pleasure (positive valence) than unfamiliar songs, which elicited interest (lower arousal) but limited pleasure (neutral valence). Moreover, parents primarily sang playsongs, which elicit higher infant arousal than lullabies (Cirelli et al., 2019). If infants' favorite songs had been lullabies, lower arousal levels might have resulted.

The principal contribution of the present study is the finding that parental singing interactions involving highly familiar songs ameliorate infant distress more effectively than comparable interactions involving unfamiliar songs or speech. From the infant's perspective, the still-face episode featured their primary caregiver behaving in an uncharacteristic, perhaps frightening, manner-looking directly at the infant while remaining silent and immobile. By contrast, the reunion with familiar songs reinstated highly familiar and highly valued caregiving behavior, as parents sang infants' favorite song, presumably in a ritualized manner with characteristic pitch, tempo, and expressive style (Bergeson \& Trehub, 2002; Trehub, Plantinga, \& Russo, 2016). Perhaps infants link these familiar sung performances to pleasant feelings or situations experienced previously, as do listeners throughout the lifespan (Krumhansl \& Zupnick, 2013). The efficacy of familiar songs in reducing infant distress adds to their documented consequences for infants' social choices (Mehr et al., 2016; Mehr \& Spelke, 2017), prosocial behavior (Cirelli \& Trehub, 2018), and propensity to move rhythmically (Cirelli \& Trehub, 2019).

Parents' renditions of familiar songs featured more smiling, rhythmic movement, and gesture, prompted by parents' greater ease with these songs, infants' positive response eliciting heightened parental expressiveness (Trehub et al., 2016), or both. Future research is necessary to 
pinpoint the features of familiar songs (melody, lyrics, stereotyped performances, expressive aspects) that underlie their efficacy in promoting infant attention and positive affect.

The present study confirms and extends findings reported in Ghazban's (2013) doctoral dissertation - greater distress reduction and lower arousal for singing than for speech reunionsbut differs in other respects. For example, Ghazban found decreased arousal over the course of her 1.5-min singing reunion, but increased arousal for maternal speech. By contrast, we found elevated arousal throughout our 2-min reunion for the repeatedly sung favorite song or for speech. Undoubtedly, Ghazban's very brief still-face episode (20 s) generated less distress and lower arousal than our extended episode, which continued for $60 \mathrm{~s}$ unless infants exhibited sustained distress earlier. Moreover, parents' singing of various familiar songs (Ghazban's study) may have been more engaging than repetitions of the same song. In any case, higher arousal levels generated by prolonged stress are likely to be more resistant to simple interventions such as singing, requiring more robust interventions such as carrying with movement.

The effects of age were minimal. Although 10-month-olds exhibited more distress and greater attention to parents than 8-month-olds, there were no interactions between age and the effects of interest. Even younger infants, who have robust memory for songs (Mehr et al., 2016) but lesser efficacy in self-regulation (Rothbart, Posner, \& Kieras, 2006). are important targets for future research on the affect-regulatory consequences of familiar songs.

In sum, our findings highlight the dynamic regulation of infant attention, affect, and arousal by parents' multimodal singing of familiar songs. The efficacy of familiar songs for infant emotion regulation, as in the present study, and in infant social regulation, as in previous research (Cirelli \& Trehub, 2018; Mehr et al., 2016; Mehr \& Spelke, 2017), warrants their inclusion in interventions for parenting stress, which has been linked to dysfunctional reactions 
to infant distress (e.g., Leerkes \& Siepak, 2006). In support of this proposal, toddlers exposed to regular parental singing use songs for self-regulation (Sole, 2017). Singing, by reducing infants' and parents' distress, may enhance dyadic bonds and caregivers' feelings of self-efficacy. 


\section{References}

Adamson, L. B., \& Frick, J. E. (2003). The still face: A history of a shared experimental paradigm. Infancy, 4, 451-473. https://doi.org/10.1207/S15327078IN0404_01

Bell, S. M., \& Ainsworth, M. D. S. (1972). Infant crying and maternal responsiveness. Child Development, 43, 1171-1190. https://www.doi.org/10.2307/1127506

Benedek, M., \& Kaernbach, C. (2010). Decomposition of skin conductance data by means of nonnegative deconvolution. Psychophysiology, 47, 647-658. https://www.doi.org/ 10.1111/j.1469-8986.2009.00972.x

Bergeson, T., \& Trehub, S. (2002). Absolute pitch and tempo in mothers' songs to infants. Psychological Science, 13, 72-75. http://doi.org/10.1111/1467-9280.00413

Bergeson, T. R., \& Trehub, S. E. (2007). Signature tunes in mothers' speech to infants. Infant Behavior and Development, 30, 648-654. https://doi.org/10.1016/j.infbeh.2007.03.003

Bornstein, M. H., Putnick, D. L., Rigo, P., Esposito, G., Swain, J. E., Suwalsky, J. T. D., ... Venuti, P. (2017). Neurobiology of culturally common maternal responses to infant cry. Proceedings of the National Academy of Sciences, 114, E9465-E9473. https://doi.org/10.1073/pnas. 1712022114

Cirelli, L. K., \& Trehub, S. E. (2018). Infant prosocial behavior toward singing and non-singing partners. Music \& Science, 1. https://doi.org/10.1177/2059204318761622

Cirelli, L. K., \& Trehub, S. E. (2019). Dancing to Metallica and Dora: Case study of a 19-monthold. Frontiers in Psychology, 10, 1073. https://doi.org/10.3389/fpsyg.2019.01073

Cirelli, L. K., Jurewicz, Z., \& Trehub, S. E. (2019). Effects of maternal singing style on motherinfant arousal and behavior. Journal of Cognitive Neuroscience. https://doi.org/10.1162/jocn_a_01402 
Cohrdes, C. Wrzus, C., Frisch, S., \& Riediger, M. (2017). Tune yourself in: Valence and arousal preferences in music-listening choices from adolescence to old age. Developmental Psychology, 53, 1777-1794. https://doi.org/10.1037/dev0000362

Cohen, L. L. (2002). Reducing infant immunization distress through distraction. Health Psychology, 21, 207-211. http://doi.org/10.1037/0278-6133.21.2.207

Cooper, R. P., \& Aslin, R. N. (1990). Preference for infant-directed speech in the first month after birth. Child Development, 61, 1584-1595. https://doi.org/10.2307/1130766

Corbeil, M., Trehub, S. E., \& Peretz, I. (2013). Speech vs. singing: Infants choose happier sounds. Frontiers in Psychology, 4, 372. https://doi.org/ 10.3389/fpsyg.2013.00372

Corbeil, M., Trehub, S. E., \& Peretz, I. (2016). Singing delays the onset of infant distress. Infancy, 21, 373-391. https://doi.org/10.1111/infa.12114

Costa-Giomi, E. (2014). Mode of presentation affects infants' preferential attention to singing and speech. Music Perception, 32, 160-169. https://doi.org/10.1525/mp.2014.32.2.160

Costa-Giomi, E., \& Ilari, B. (2014). Infants' preferential attention to sung and spoken stimuli. Journal of Research in Music Education, 62, 188-194. https://doi.org/10.1177/0022429414530564

Costa-Giomi, E. (2014). Mode of presentation affects infant's preferential attention to singing and speech. Music Perception, 32, 160-169. https://doi.org/10.1525/mp.2014.32.2.160

Dean, B. (2019). Spontaneous singing and musical agency in the everyday home lives of threeand four-year-old children. In S. Young, \& B. Ilari (Eds.), Music in early childhood: Multidisciplinary perspectives and inter-disciplinary exchanges (Vol. 27, pp. 103-118). Cham, Switzerland: Springer. 
Eisenberg, N., Cumberland, A., \& Spinrad, T. L. (1998). Parental socialization of emotion. Psychological Inquiry, 9, 241-273. https://doi.org/10.1207/s15327965pli0904_1

Esposito, G., Yoshida, S., Ohnishi, R., Tsuneoka, Y., del Carmoen Rostagno, M., Yokota, S., ... Kuroda, K. O. (2013). Infant calming responses during maternal carrying in humans and mice. Current Biology, 23, 739-745. https://doi.org/10.1016/j.cub.2013.03.041

Falk, D. (2004). Prelinguistic evolution in early hominins: whence motherese? Behavioral and Brain Sciences, 27, 491-541. https://doi.org/ 10.1017/s0140525x04000111

Faul, F., Erdfelder, E., Lang, A., \& Buchner, A. (2007). A flexible statistical power analysis program for the social, behavioral, and biomedical sciences. Behavior Research Methods 39, 175-191. https://doi.org/10.3758/BF03193146

Fernald, A. (1985). Four-month-old infants prefer to listen to motherese. Infant Behavior and Development, 8, 181-195. https://doi.org/10.1016/S0163-6383(85)80005-9

Fernald, A., \& Simon, T. (1984). Expanded intonation contours in mothers' speech to newborns. Developmental Psychology, 20, 104-113. http://doi.org/10.1037/0012-1649.20.1.104

Ghazban, N. (2013). Emotion regulation in infants using maternal singing and speech. Doctoral dissertation. Ryerson University, Toronto.

Jahromi, L. B., \& Stifter, C. A. (2007). Individual differences in the contribution of maternal soothing to infant distress reduction. Infancy, 11, 255-269. https://doi.org/10.1111/j.15327078.2007.tb00226.x

Johnston, R. R. (2016). The effect of repetition on preference ratings for select unfamiliar musical examples: Does preference transfer? Psychology of Music, 44, 514-526. https://doi.org/10.1177/0305735615577248

Jovanovic, T., Megna, N. L., \& Maestripieri, D. (2000). Early maternal recognition of offspring 
vocalizations in rhesus macaques (Macaca mulatta). Primates, 41, 421-428. https://doi.org/10.1007/BF02557653

Krumhansl, C. L., \& Zupnick, J. A. (2013). Cascading reminiscence bumps in popular music. Psychological Science, 24, 2057-2068. http://doi.org/10.1177/0956797613486486

Lausberg, H., and Sloetjes, H. (2009). Coding gestural behavior with the NEUROGES-ELAN system. Behavior Research Methods, 41, 841-849. https://doi.org/10.3758/BRM.41.3.841

Leerkes, E. M., Blankson, A. N., \& O’Brien, M. (2009). Differential effects of maternal sensitivity to infant distress and nondistress on social-emotional functioning. Child Development, 80, 762-775. https://doi.org/ 10.1111/j.1467-8624.2009.01296.x

Leerkes, E. M., \& Siepak, K. J. (2006). Attachment linked predictors of women's emotional and cognitive responses to infant distress. Attachment \& Human Development, 8, 11-32. https://doi.org/10.1080/14616730600594450

Lingle, S., \& Riede, T. (2014). Deer mothers are sensitive to infant distress vocalizations of diverse mammalian species. The American Naturalist, 184, 510-522. http://doi.org/10.5061/dryad.pj891.

Longhi, E. (2009). 'Songese': Maternal structuring of musical interaction with infants. Psychology of Music, 37, 195-213. https://doi.org/10.1177/0305735608097042

Lonsdale, A. J. \& North, A. C. (2011). Why do we listen to music? A uses and gratification analysis. British Journal of Psychology, 102, 108-134. https://doi.org/10.1348/000712610X506831

Margulis, E. H. (2013). Repetition and emotive communication in music versus speech. Frontiers in Psychology, 4, 167. https://doi.org/10.3389/fpsyg.2013.00167

Margulis, E.H. (2014). On repeat: How music plays the mind. New York: Oxford University 
Press.

Mehr, S. A., Singh, M., Knox, D., Ketter, D. M., Pickens-Jones, D., Atwood, S., ... Glowacki, L. (2019). Universality and diversity in human song. Science, 366, eaax0868:1-17. https://doi.org/ 10.1126/science.aax0868

Mehr, S. A., Song, L. A., \& Spelke, E. S. (2016). For 5-month-old infants, melodies are social. Psychological Science, 27, 486-501. https://doi.org/10.1177/0956797615626691

Mehr, S. A., \& Spelke, E. S. (2017). Shared musical knowledge in 11-month-old infants. Developmental Science, 21, e12542. https://doi.org/10.1111/desc.12542

Mesman, J., van Ijzendoorn, M. H., \& Bakermans-Kranenburg, M. J. (2009). The many faces of the still-face paradigm: A review and meta-analysis. Developmental Review, 29, 120-162. http://doi.org/10.1016/j.dr.2009.02.001

Nakata, T., \& Trehub, S. (2004). Infants' responsiveness to maternal speech and singing. Infant Behavior and Development, 27, 455-464. http://doi.org/10.1016/j.infbeh.2004.03.002

Nakata, T., \& Trehub, S. (2011). Expressive timing and dynamics in infant-directed and noninfant-directed singing. Psychomusicology: Music, Mind and Brain, 21, 130-138. https://doi.org/10.5084/pmmb2010/21/xxx

Partanen, E., Kujala, T., Tervaniemi, M., \& Huotilainen, M. (2013). Prenatal music exposure induces long-term neural effects. PloS One, 8, e78946. https://doi.org/10.1371/journal.pone.0078946

Pereira, C. S., Teixeira, J., Figueiredo, P., Xavier, J., Castro, S. L., \& Brattico, E. (2011). Music and emotions in the brain: Familiarity matters. PLoS ONE, 6, e27241. https://doi.org/10.1371/journal.pone.0027241

Plantinga, J., \& Trainor, L. J. (2005). Memory for melody: Infants use a relative pitch code. 
Cognition, 98, 1-11. https://doi.org/1016/j.cognition.2004.09.008

Plantinga, J., \& Trainor, L. J. (2009). Melody recognition by two-month-old infants. The Journal of the Acoustical Society of America, 125, EL58-62. https://doi.org/10.1121/1.3049583

Rothbart, M. K., Posner, M. I., \& Kieras, J. (2006). Temperament, attention, and the development of self-regulation. In K. McCartney \& D. Phillips (Eds.), Blackwell handbook of early childhood development (pp. 338-357). Malden, MA: Blackwell Publishing.

Saarikallio, S., \& Erkkilä, J. (2007). The role of music in adolescents' mood regulation. Psychology of Music, 35, 88-109. https://doi.org/10.1177/0305735607068889

Savage, P. E., Brown, S., Sakai, E., \& Currie, T. E. (2015). Statistical universals reveal the structures and functions of human music. Proceedings of the National Academy of Sciences, 112, 8987-8992. https://doi.org/10.1073/pnas.1414495112

Shenfield, T., Trehub, S. E., \& Nakata, T. (2003). Maternal singing modulates infant arousal. Psychology of Music, 31, 365-375. https://doi.org/10.1177/03057356030314002

Sole, M. (2017). Crib song: Insights into functions of toddlers' private spontaneous singing. Psychology of Music, 45, 172-192. https://doi.org/10.1177/0305735616650746

Soley, G., \& Spelke, E. S. (2016). Shared cultural knowledge: Effects of music on young children's social preferences. Cognition, 148, 106-116. https://doi.org/10.1016/j.cognition.2015.09.017

Trainor, L. J. (1996). Infant preferences for infant-directed versus noninfant-directed playsongs and lullabies. Infant Behavior and Development, 19(1), 83-92. https://doi.org/10.1016/S0163-6383(96)90046-6

Trehub, S. E., Plantinga, J., \& Russo, F. A. (2016). Maternal vocal interactions with infants: Reciprocal visual influences. Social Development, 25, 665-683. 
http://doi.org/10.1111/sode.12164

Trehub, S., and Trainor, L. (1998). Singing to infants: Lullabies and play songs. Advances in Infancy Research, 12, 43-77.

Tronick, E., Als, H., Adamson, L., Wise, S., \& Brazelton, T. B. (1978). Infants' response to entrapment between contradictory messages in face-to-face interaction. Journal of the American Academy of Child and Adolescent Psychiatry, 17, 1-13. https://doi.org/10.1016/S0002-7138(09)62273-1

Tsang, C. D., Falk, S., \& Hessel, A. (2017). Infants prefer infant-directed song over speech. Child Development, 88, 1207-1215. https://doi.org/10.1111/cdev.12647

van den Bosch, I., Salimpoor, V. N., \& Zatorre, R. J. (2013). Familiarity mediates the relationship between emotional arousal and pleasure during music listening. Frontiers in Human Neuroscience, 7, 574. https://doi.org/10.3389/fnhum.2013.00534

Weinberg, M. K., \& Tronick, E. Z. (1996). Infant affective reactions to the resumption of maternal interaction after the still-face. Child Development, 67, 905-914. http://doi.org/10.2307/1131869

Weiss, M. W., Trehub, S. E., \& Schellenberg, E. G. (2012). Something in the way she sings: Enhanced memory for vocal melodies. Psychological Science, 23, 1074-1078. https://doi.org/10.1177/0956797612442552

Weiss, M. W., Schellenberg, E. G., Trehub, S. E., \& Dawber, E. (2015). Enhanced processing of vocal melodies in childhood. Developmental Psychology, 51, 370-377. https://doi.org/10.1037/a0038784

Zeifman, D. M. (2015). An ethological analysis of human infant crying: Answering Tinbergen's four questions. Developmental Psychobiology, 39, 265-285. 
http://doi.org/10.1002/dev.1005 